\title{
A Meta-analysis of the effects of Exercise Training on Left Ventricular Remodeling Following Myocardial Infarction: Start early and go longer for greatest exercise benefits on remodeling
}

Mark Haykowsky ${ }^{1 *}$, Jessica Scott ${ }^{2}$, Ben Esch², Don Schopflocher ${ }^{3}$, Jonathan Myers ${ }^{4}$, lan Paterson ${ }^{5}$, Darren Warburton ${ }^{2}$, Lee Jones ${ }^{6}$ and Alexander M Clark ${ }^{7}$

\begin{abstract}
Background: The effects of variations in exercise training on Left ventricular (LV) remodeling in patients shortly after Myocardial Infarction (MI) are important but poorly understood.

Methods: Systematic review incorporating meta-analysis using meta-regression. Studies were identified via systematic searches of: OVID MEDLINE (1950 to 2009), Cochrane Central Register of Controlled Trials (1991 to 2009), AMED (1985 to 2009), EMBASE (1988 to 2009), PUBMED (1966 to 2009), SPORT DISCUS (1975 to 2009), SCOPUS (1950 to 2009) and WEB OF SCIENCE (1950 to 2009) using the medical subject headings: myocardial infarction, post myocardial infarction, post infarction, heart attack, ventricular remodeling, ventricular volumes, ejection fraction, left ventricular function, exercise, exercise therapy, kinesiotherapy, exercise training. Reference lists of all identified studies were also manually searched for further relevant studies. Studies selected were randomized controlled trials of exercise training interventions reporting ejection fraction (EF) and/or ventricular volumes in patients following recent $\mathrm{Ml}$ ( $\leq 3$ months) post-Ml patients involving control groups. Studies were excluded if they were not randomized, did not have a 'usual-care' control (involving no exercise), evaluated a non-exercise intervention, or did not involve human subjects. Non-English studies were also excluded.

Results: After screening of 1029 trials, trials were identified that reported EF (12 trials, $n=647$ ), End Systolic Volumes (ESV) (9 trials, $n=475)$ and End Diastolic Volumes (EDV) (10 trials, $n=512)$. Meta-regression identified that changes in EF effect size difference decreased as the time between $\mathrm{Ml}$ and initiation of the exercise program lengthened, and increased as the duration of the program increased $\left(Q=25.48, \mathrm{df}=2, \mathrm{p}<0.01, R^{2}=0.76\right.$ ). Greater reductions in ESV and EDV (as indicated by effect size decreases) occurred with earlier initiation of exercise training and with longer training durations ( $E S V: Q=23.89, d f=2, p<0.05, R^{2}=0.79 ; E D V: Q=27.42, d f=2, p<$ $0.01, R^{2}=0.83$ ). Differences remained following sensitivity analysis. Each week that exercise was delayed required an additional month of training to achieve the same level of benefit on LV remodeling.
\end{abstract}

Conclusions: Exercise training has beneficial effects on LV remodeling in clinically stable post-MI patients with greatest benefits occurring when training starts earlier following MI (from one week) and lasts longer than 3 months.

\footnotetext{
* Correspondence: Mark.Haykowsky@ualberta.ca

'Faculty of Rehabilitation Medicine, University of Alberta, Edmonton, Canada

Full list of author information is available at the end of the article
} 


\section{Background}

There is strong and consistent evidence that exercise after a myocardial infarction (MI) improves overall and cardiovascular-related mortality [1,2]. In low, middle and high income countries, patients who exercise regularly are over $30 \%$ less likely to experience further MI, stroke or death [3]. However, the mechanisms of these mortality benefits are not well understood.

Left ventricular (LV) remodeling is an accurate predictor of cardiac mortality following MI [4] but it is not clear how exercise effects LV remodeling. In some past trials, aerobic training led to decreases in LV end-diastolic (EDV) and end-systolic volumes (ESV) and increases in ejection fraction (EF) [5-7]. In other trials, exercise training led to increased LV volumes [8,9] and decreased EF [8]. Still further, other trials identified that following MI exercise training does not alter LV volumes [10-14] or EF [11-14]. Though the effects of LV remodeling are likely to vary based on the characteristics of populations and exercise interventions, it is not known why these variations occur [15].

Understanding these inconsistencies and the effects of exercise on LV remodeling is important because this knowledge could be used to heighten the benefits of exercise after MI. Though arguably essential for effective support and health services, recent guidelines on physical activity after MI do not provide any recommendations on the key but basic issues of when exercise should commence after MI and how long supervised exercise should continue to ensure or maximize benefits [2]. Information on these design characteristics should provide more effective and useful evidence for health professionals [16]. Consequently we performed a systematic review and meta-analysis to assess the overall effects of exercise training on LV remodeling in clinically stable post-MI patients.

\section{Methods}

\section{Data sources}

A searched was undertaken of OVID MEDLINE (1950 to 2009), Cochrane Central Register of Controlled Trials (1991 to 2009), AMED (1985 to 2009), EMBASE (1988 to 2009), PUBMED (1966 to 2009), SPORT DISCUS (1975 to 2009), SCOPUS (1950 to 2009) and WEB OF SCIENCE (1950 to 2009) using the following medical subject headings: myocardial infarction, post myocardial infarction, post infarction, heart attack, ventricular remodeling, ventricular volumes, ejection fraction, left ventricular function, exercise, exercise therapy, kinesiotherapy, exercise training. Reference lists of all identified studies were also manually searched for further relevant investigations.

\section{Study selection}

Two investigators ( $\mathrm{MH}$ and $\mathrm{AC}$ ) independently reviewed the titles and abstracts of all citations to identify studies reporting the effect of exercise training on EF and/or ventricular volumes in recent ( $\leq 3$ months) post-MI patients. We excluded trials that were not randomized, did not have a usual care control group, non-exercise intervention, exercise and other intervention, and nonhuman studies. We also excluded non-English articles.

\section{Data extraction and quality assessment}

Two authors ( $\mathrm{MH}$ and $\mathrm{BE}$ ) extracted relevant outcome data and any disagreement was resolved by consensus in discussion with AC. When necessary, original investigators were contacted to clarify data or provide additional data; authors for 3 studies provided further information. Quality was assessed using the Jadad scale [17].

\section{Data synthesis and analysis}

All data was entered into SPSS files and analyzed with SPSS v15 software utilizing meta-analysis and metaregression scripts created by Lipsey and Wilson [18]. The review conforms to the requirements of PRISMA reporting standards (Additional file 1). Formulae for calculation of outcomes is provided in Additional File 2.

\section{Results}

\section{Study selection}

After initial review of 1,033 citations (Figure 1), 19 papers were reviewed in full; of these, seven were excluded. Reasons for this exclusion were: EF data incomplete or un-extractable $(n=3)$, non-randomized

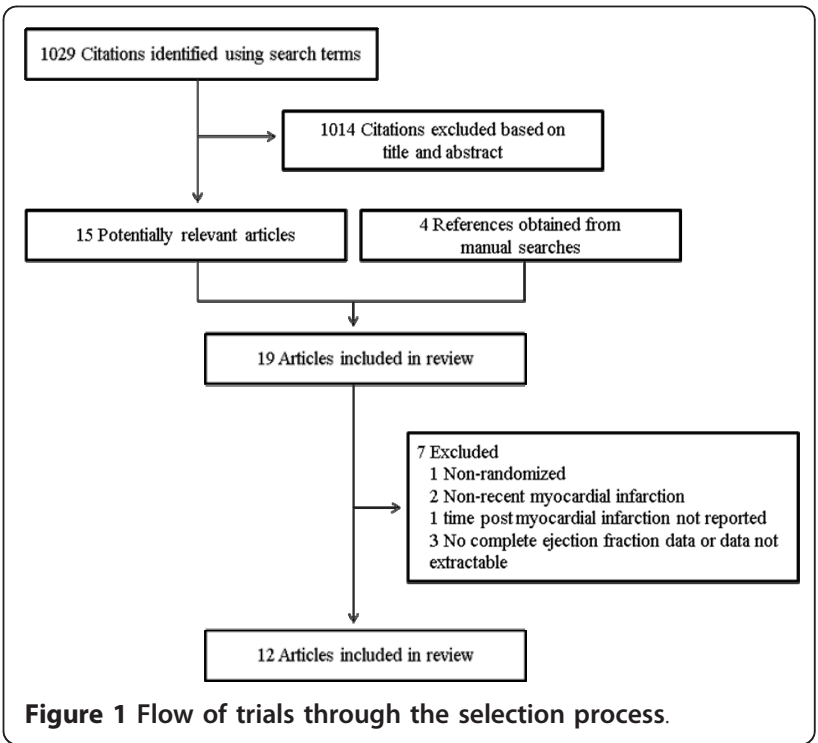


design ( $n=1)$, time from MI to initiation of exercise training was unreported $(\mathrm{n}=1)$, inclusion of patients experiencing MI $>3$ months $(n=2)$. One trial [19] randomly assigned subjects 'a priori' to exercise or control groups based on baseline EF ( $\leq 30$ and $>30 \%$ ). Accordingly, data for these sub-groups were analyzed separately.

\section{Study characteristics}

The selected studies [5-7,9-14,19-21](Additional File 3) contained 647 post-MI patients (mean age: 55 years) with impaired LV systolic function (weighted mean $\mathrm{EF}=44 \%$ ). Trials incorporated aerobic training at $60 \%$ to $80 \%$ of baseline peak oxygen uptake (or heart rate) for 20 to 180 minutes per session (Table 1). The length of training program was 1 to 6 months in duration (Table 1). All trials reported pre and post measures for outcome variable for both treatment groups and for control groups. No trial described randomization procedures or blinding methods. Consequently, trials tended to be assessed as being of low to moderate quality.

Three outcome variables were chosen for analysis. The primary variable was EF for which 12 trials reported data $(\mathrm{n}=647)$. The secondary outcome variables were ESV and EDV for which data was only provided for a subset of trials: ESV ( 9 trials, $\mathrm{n}=475)$ and EDV (10 trials, $\mathrm{n}=512$ ).

\section{Initial analysis}

As the studies had high levels of statistical, clinical and methodological heterogeneity - as evident for example in the initial meta-analysis of EF (Cochran's $\mathrm{Q}=33.57$, $\mathrm{df}=12, \mathrm{p}<0.01)$ and variations in effect size differences for each outcome variable, pooling of the results from the trials in a sub-analysis was inappropriate [22]. Therefore, we performed meta-regression of post-infarct LV remodeling. The effects of elements of the exercise interventions identified a priori for analysis were: time post-MI to initiation of exercise training program and length of training program [23].

\section{Exercise training and ejection fraction}

Meta-regression identified that change in EF effect size difference decreased as the time between MI and initiation of the exercise program lengthened, and increased as the duration of the program increased (Figure 2). Overall, these changes accounted for a significant proportion of the variations in outcomes across the studies $\left(\mathrm{Q}=25.48, \mathrm{df}=2, \mathrm{p}<0.01, \mathrm{R}^{2}=0.76\right)$ (Table 2). That is, when study level differences in average time to initiate and average length of program are considered the trials become comparable.

\section{Exercise training and ventricular volumes}

A sufficient number of trials reported data on ESV (9 trials, $\mathrm{n}=475)$ [5-7,9-14] and EDV (10 trials, $\mathrm{n}=$ 512) $[5-7,9-14,20]$ to allow meta-regression of these outcomes. Similar to EF, effects on LV volumes were not homogeneous across studies (ESV, $\mathrm{Q}=30.12, \mathrm{df}=8$, $\mathrm{p}<0.01 ; \mathrm{EDV}, \mathrm{Q}=33.03, \mathrm{df}=9, \mathrm{p}<0.01)$. Greater reductions in ESV and EDV (as indicated by effect size decreases) occurred with earlier initiation of exercise training and with longer training durations (Tables 3 and 4, Figures 3 and 4). These differences accounted for a significant proportion of the heterogeneity for ESV $\left(\mathrm{Q}=23.89, \mathrm{df}=2, \mathrm{p}<0.05, \mathrm{R}^{2}=0.79\right)$ and $\mathrm{EDV}$

Table 1 Description of exercise training program

\begin{tabular}{|c|c|c|c|c|c|}
\hline Study & $\begin{array}{c}\begin{array}{c}\text { Frequency } \\
\text { (days/week) }\end{array} \\
\end{array}$ & Intensity & Exercise duration (min/session) & Mode & Program length $(\mathrm{mn})$ \\
\hline Giallauria et al [6] & 3 & $60-70 \% \mathrm{VO}_{2 \text { peak }}$ & 30 & Cycle & 6 \\
\hline Giallauria et al [5] & 3 & $60-70 \% \mathrm{VO}_{2 \text { peak }}$ & 30 & Cycle & 6 \\
\hline Giallauria et al [12] & 3 & $70 \% \mathrm{VO}_{2 \text { peak }}$ & 30 & Cycle & 3 \\
\hline Giallauria et al [13] & 3 & $60 \% \mathrm{VO}_{2 \text { peak }}$ & 30 & Cycle & 3 \\
\hline Giannuzzi et al [7] & $3-7$ & $80 \%$ peak HR & $\begin{array}{c}30 \\
>30 \text { min }\end{array}$ & $\begin{array}{l}\text { Cycle } \\
\text { Walk }\end{array}$ & 6 \\
\hline Koizumi et al [14] & 7 & Moderate speed & 30 & Walk & 3 \\
\hline Kubo et al [9] & 3 & $\mathrm{HR}$ at $\mathrm{VT}$ & 20 min, twice/day & $\begin{array}{l}\text { Cycle } \\
\text { Walk }\end{array}$ & 3 \\
\hline Dubach et al [11] & $4-7$ & $60-70 \%$ HRR & $\begin{array}{l}45 \\
120\end{array}$ & $\begin{array}{l}\text { Cycle } \\
\text { Walk }\end{array}$ & 2 \\
\hline Giannuzzi et al [10] & $3-7$ & $80 \%$ peak HR & $\begin{array}{c}30 \\
>30\end{array}$ & $\begin{array}{l}\text { Cycle } \\
\text { Walk }\end{array}$ & 6 \\
\hline Heldal et al [20] & 5 & $85 \%$ peak HR & 120 & $\begin{array}{c}\text { Cycle } \\
\text { Jogging }\end{array}$ & 1 \\
\hline Jette et al [19] & 7 & 70-80\% peak HR & $45-105$ & Cycle, Jogging Walk, Calisthenics & 1 \\
\hline Grodzinski et al [21] & 5 & $80 \%$ peak HR & $30-180$ & Cycle, Jog Walk, Swim Calisthenics & 1 \\
\hline
\end{tabular}

(Heart rate; HRR: Heart rate reserve; $\mathrm{VO}_{2 \text { peak, }}$ peak oxygen consumption; VT: Ventilation threshold). 


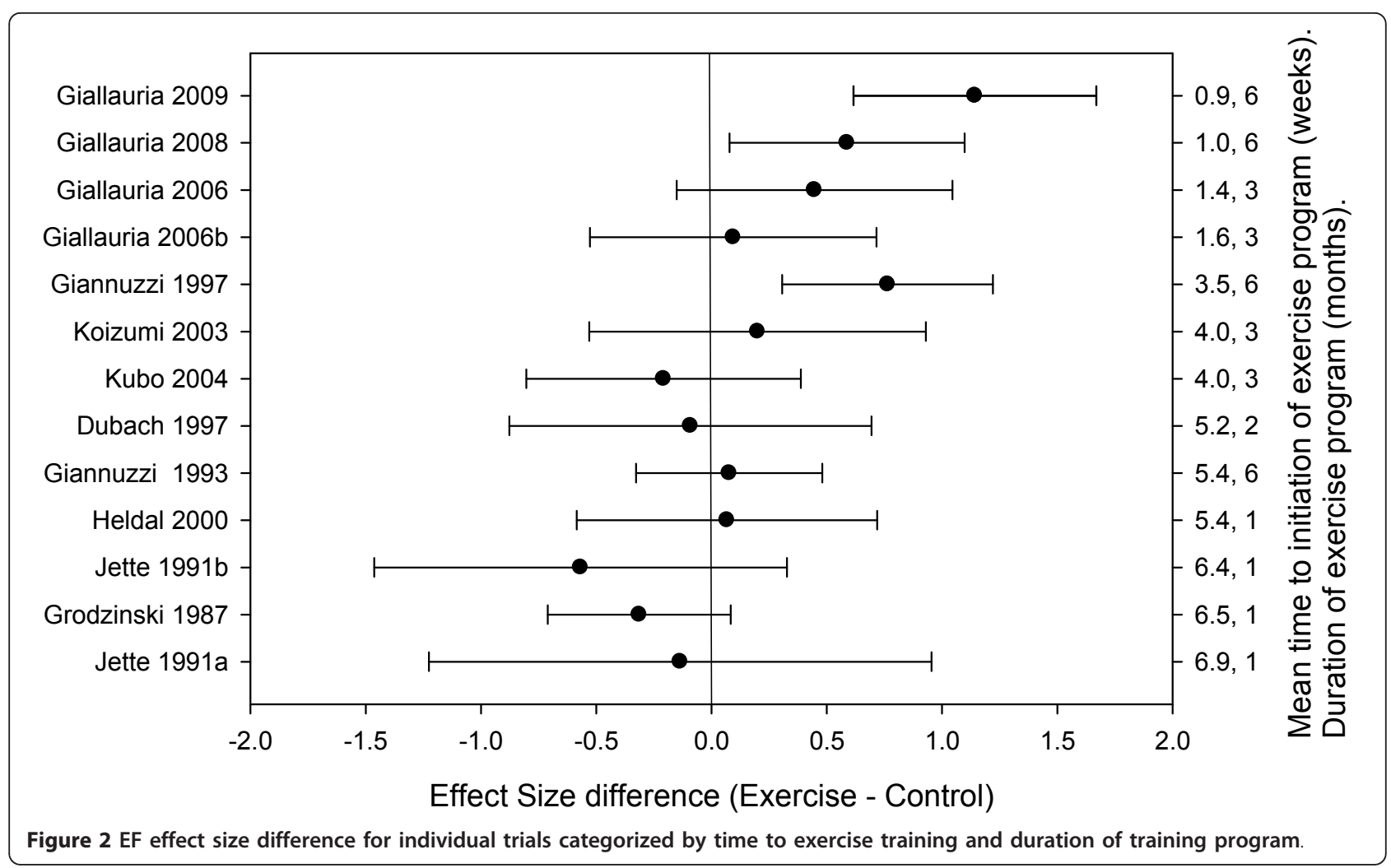

$\left(\mathrm{Q}=27.42, \mathrm{df}=2, \mathrm{p}<0.01, \mathrm{R}^{2}=0.83\right)$. As with $\mathrm{EF}$ effect size, when study level differences in average time to initiate and average length of program were considered, effects on ESV and EDV became comparable.

\section{Sensitivity Analysis}

The findings may be influenced strongly by a small number of trials which evaluated exercise training after around one week. Analyses were therefore repeated excluding the four trials with the shortest latency to initiation of the exercise program $[5,6,12,13]$. After this removal, the analysis no longer had sufficient power to demonstrate significant effects. However, the regression coefficients remained of similar size and direction (For time to initiate: -0.119 to -0.178 ( $\mathrm{p}<0.15$ ); for length from 0.098 to $0.069(\mathrm{p}<0.25))$ suggesting that the trends identified in the full analysis remained even when these trials are excluded. Removing the same trials from the analyses of ESV and EDV reduced the number of

Table 2 Meta-Regression of the change in EF effect size difference

\begin{tabular}{llll}
\hline & B & Standard Error & Probability \\
\hline Constant & 0.314 & 0.315 & $\mathrm{~ns}$ \\
Time to Initiate & -0.119 & 0.045 & $\mathrm{p}<0.05$ \\
Length & 0.098 & 0.046 & $\mathrm{p}<0.05$ \\
\hline
\end{tabular}

trials in the analyses more dramatically (5 and 6 trials respectively). In both re-analyses, the coefficients for time to initiate again remained in the same direction but decreased substantially in magnitude (ESV: 0.246 to 0.076 and EDV: 0.189 to 0.059 ) and were no longer significant. Yet, the coefficients for program length were more stable (ESV: -0.249 to $-0.138, \mathrm{p}<0.10$, and EDV: -0.148 to $-0.13, p<0.05)$. Hence, particularly for $L V$ remodeling, the influence of time to initiation of exercise training after MI and subsequent length of training program remained after removal of the trials.

\section{Discussion}

This systematic review found that exercise training had beneficial effects on LV remodeling after myocardial infarction but that the sizes of changes were dependent on time of instigation and duration of the exercise intervention. The largest changes in LV remodeling were obtained when programs began after around 1-week

Table 3 Meta-Regression of the change in ESV effect size difference

\begin{tabular}{llll}
\hline & B & Standard Error & Probability \\
\hline Constant & -0.07 & 0.45 & $\mathrm{~ns}$ \\
Time to Initiate & 0.246 & 0.072 & $\mathrm{p}<0.01$ \\
Length & -0.249 & 0.078 & $\mathrm{p}<0.01$ \\
\hline
\end{tabular}


Table 4 Meta-Regression of the change in EDV effect size difference

\begin{tabular}{llll}
\hline & B & Standard Error & Probability \\
\hline Constant & -0.186 & 0.54 & $\mathrm{~ns}$ \\
Time to Initiate & 0.189 & 0.051 & $\mathrm{p}<0.01$ \\
Length & -0.148 & 0.051 & $\mathrm{p}<0.01$ \\
\hline
\end{tabular}

post MI hospital discharge and lasted for 6 months. For ESV, a strong predicator of mortality post-MI [4], each one-week delay in initiating exercise training would require an additional month of training to obtain a comparable reduction in ESV. Similarly, delaying exercise training by one week after a MI would require an additional month of training to attain the same change in LVEF.

As with all systematic reviews, the conclusions of this review are only as strong as the quality of the component studies. The trials included predominantly younger males with reduced systolic function though there is unlikely to be differences in effects by sex, future trials should include a greater proportion of women. In the trials, the type and location of infarction was not widely used to stratify results and few studies measured exercise capacity. Accordingly, future trials are needed to measure and assess the specific effects of these factors on LV remodeling. The trials included were not well described and did not report all of the information required to conduct optimal analysis in the case of repeated measures. Here, a conservative alternative nevertheless showed significant findings in the metaregression. The effect sizes would have been larger if correlations between pre-and-post intervention scores had been available.

The findings are biologically plausible. Though the physiological mechanisms responsible for the anti-remodeling benefits of exercise training following MI are not well understood, they may arise from favorable improvements in coronary and peripheral vascular endothelial function, myocardial contractility, autonomic balance, or systolic and diastolic wall stress $[24,25]$. Several studies have also shown that aerobic training can elicit improvements in diastolic function and wall stress $[5,12,13,26]$. Post-training decreases in plasma pro-NT-BNP reduce EDV [5] and increase peak early mitral flow velocity $[5,12,13]$ and peak early to late mitral flow velocity ratio $[12,13]$. Aerobic-training improves autonomic balance [27] and peripheral vascular endothelial function [28]. The anti-remodeling benefits arising from exercise programs with a longer training length may explain the effects of cardiac rehabilitation attendance on survival after MI [29].

\section{Clinical implications}

There is no current recommendations [30] or consensus [31] as to when exercise training should commence

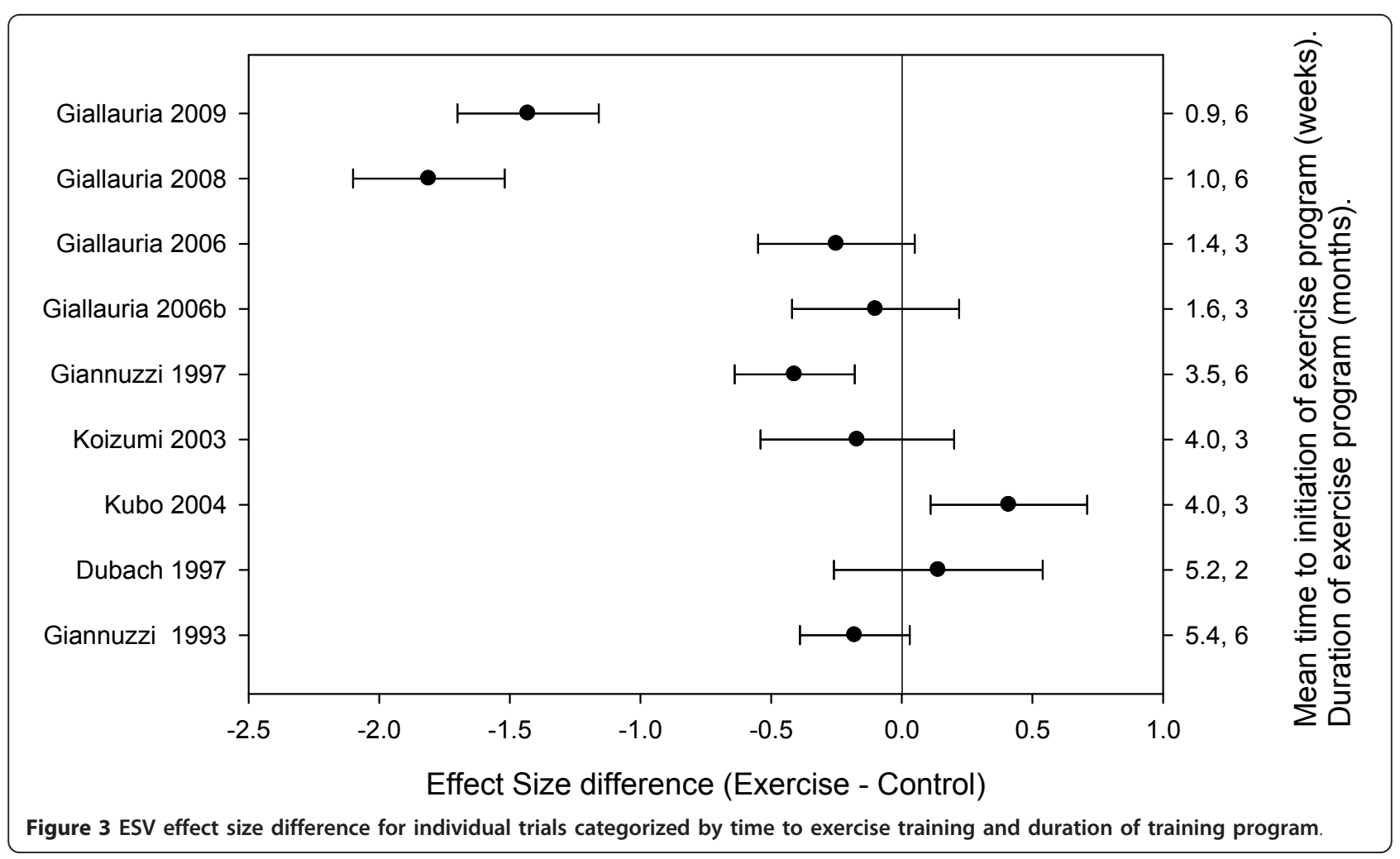




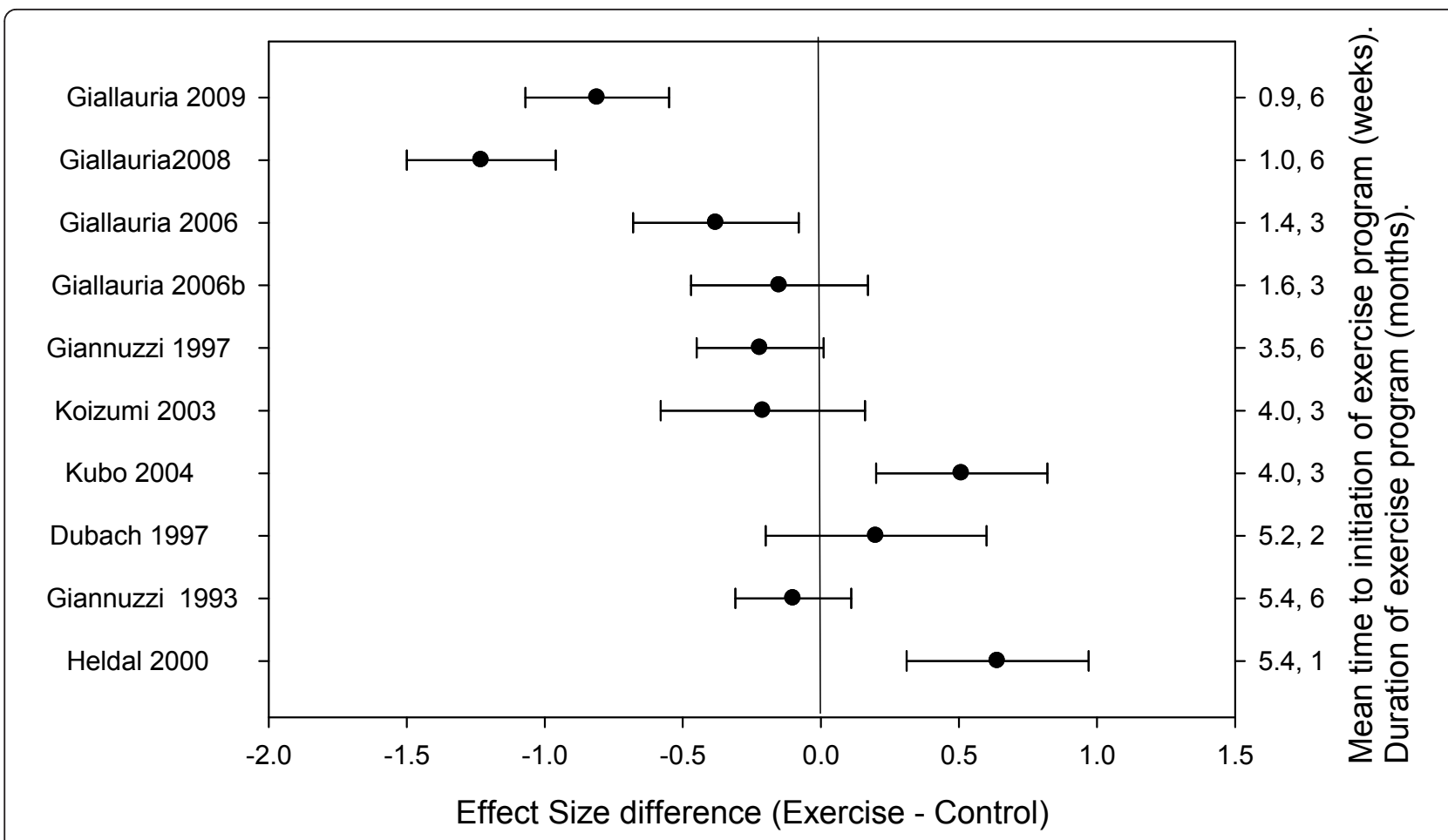

Figure 4 EDV effect size difference for individual trials categorized by time to exercise training and duration of training program.

after MI. Most cardiac rehabilitation and secondary prevention programs commence at least four to six weeks after hospital discharge [32]. To achieve maximal antiremodeling benefits, clinically stable patients after uncomplicated MI should begin aerobic exercise training earlier after hospital discharge (from one week) and should continue training for up to 6 months. As this conclusion represents a potentially significant change from current practice, it is important to take into account the size and safety of this.

Though understandable, there is no evidence from the trials in this review or other observational studies that early commencement of exercise training is harmful. Trials have indicated that risk of adverse events or complications (including: re-infarction, and revascularization ) and EF are not raised by earlier physical activity when compared to activity after 6 weeks - even when predischarge (Bruce protocol) stress tests are performed 1-week post-MI [33]. Consistent with these findings, pre-discharge exercise (Bruce protocol) stress testing is safe and feasible in the majority of post-MI patients 3 days after infarction [34]. In trials in this review, no adverse events occurred during the 6-month exercise training sessions initiated at the earliest juncture (around one week post-MI) in people with mild to moderate LV systolic dysfunction [5,6]. Moreover, clinical events were significantly lower in the trained versus control group during the 6-month period.
In addition to benefitting mortality and being safe, earlier commencement of exercise training appears to markedly increase participation in secondary prevention services. Emerging evidence from observational studies indicates that commencement of cardiac rehabilitation after one week leads to a $90 \%$ increase in participation rates compared to a commencement after four weeks [35] and a faster return to work [33].

By providing more specific guidance on basic yet pivotal program design characteristics, these findings are also likely to render existing research evidence on exercise after MI more usable to health professionals and decision-makers [16]. Despite convincing evidence of the benefits of exercise after myocardial infarction $[1,2,36,37]$, secondary prevention in clinical populations remains poor [38] and health services to promote exercise are under-utilized and poorly funded [39]. Health services, including different forms of cardiac rehabilitation $[36,37,40]$ should be used more widely to promote exercise earlier and for longer after MI.

\section{Conclusions}

Exercise training has beneficial effects on LV remodeling after myocardial infarction. Exercise earlier after infarction (around 1 week) and for longer improved LV remodeling. There is a need for future high quality randomized controlled trials of exercise intervention early post myocardial infarction on LV remodeling. 


\section{Additional material}

\section{Additional file 1: PRISMA Checklist. A checklist of items reported in} the review.

Additional file 2: Formulae of calculation of outcomes. A description of the formulae through which outcomes were calculated.

Additional file 3: Description of included studies. Studies included in the review.

\section{Acknowledgements and Funding}

Dr. Haykowsky had full access to all of the data in the study and takes responsibility for the integrity of the data and the accuracy of the data analysis.

AMC and MH received funding from the Canadian Institutes of Health Research via career awards. The organization had no influence or involvement in this publication.

\section{Author details}

${ }^{1}$ Faculty of Rehabilitation Medicine, University of Alberta, Edmonton, Canada. ${ }^{2}$ Cardiovascular Physiology and Rehabilitation Laboratory, University of British Columbia, Vancouver, British Columbia, Canada. ${ }^{3}$ School of Public Health Sciences, University of Alberta, Edmonton, AB, Canada. ${ }^{4}$ Cardiology Division (111C), VA Palo Alto Health Care System, Stanford University, Palo Alto, CA, USA. ${ }^{5}$ Faculty of Medicine, University of Alberta, Edmonton, AB, Canada. ${ }^{6}$ Department of Radiation Oncology, Duke University Medical Center, Durham, NC, USA. ${ }^{7}$ Faculty of Nursing, University of Alberta, Edmonton, AB, Canada.

\section{Authors' contributions}

Conception: MH, AMC, DS; Design: $M H, A M C$, DS; Acquisition of data: $M H$ AMC, DS, JS, BE.; Analysis:: MH, AMC, DS; Interpretation of data: $\mathrm{MH}, \mathrm{AMC}$, $D S, I P, D W, L J, J M$. All authors read and approve the final manuscript.

\section{Competing interests}

The authors declare that they have no competing interests.

Received: 19 January 2011 Accepted: 4 April 2011

Published: 4 April 2011

\section{References}

1. O'Connor GT, Buring JE, Yusuf S, Goldhaber SZ, Olmstead EM, Paffenbarger RS, Hennekens $\mathrm{CH}$ : An overview of randomized trials of rehabilitation with exercise after myocardial infarction. Circulation 1989, 80:234-244.

2. Oldridge NB, Guyatt GH, Fischer ME, Rimm AA: Cardiac rehabilitation after myocardial infarction. Combined experience of randomized clinical trials. JAMA 1988, 260:945-950.

3. Chow CK, Jolly S, Rao-Melacini P, Fox KAA, Anand SS: Association of Diet, Exercise, and Smoking Modification With Risk of Early Cardiovascular Events After Acute Coronary Syndromes. Circulation 2010, 121:750-758.

4. White HD, Norris RM, Brown MA, Brandt PW, Whitlock RM, Wild CJ: Left ventricular end-systolic volume as the major determinant of survival after recovery from myocardial infarction. Circulation 1987, 76:44-51.

5. Giallauria F, Cirillo P, Lucci R, Pacileo M, De Lorenzo A, D'Agostino M, Moschella S, Psaroudaki M, Del Forno D, Orio F, et al: Left ventricular remodelling in patients with moderate systolic dysfunction after myocardial infarction: favourable effects of exercise training and predictive role of $\mathrm{N}$-terminal pro-brain natriuretic peptide. Eur $\mathrm{J}$ Cardiovasc Prev Rehabil 2008, 15:113-118.

6. Giallauria F, Galizia G, Lucci R, D’Agostino M, Vitelli A, Maresca L, Orio F, Vigorito C: Favourable effects of exercise-based Cardiac Rehabilitation after acute myocardial infarction on left atrial remodeling. Int J Cardiol 2009, 136:300-306

7. Giannuzzi P, Temporelli PL, Corra U, Gattone M, Giordano A, Tavazzi L: Attenuation of unfavorable remodeling by exercise training in postinfarction patients with left ventricular dysfunction: results of the
Exercise in Left Ventricular Dysfunction (ELVD) trial. Circulation 1997 96:1790-1797.

8. Jugdutt $\mathrm{Bl}$, Michorowski $\mathrm{BL}$, Kappagoda $\mathrm{CT}$ : Exercise training after anterior $\mathrm{Q}$ wave myocardial infarction: importance of regional left ventricular function and topography. J Am Coll Cardiol 1988, 12:362-372.

9. Kubo N, Ohmura N, Nakada I, Yasu T, Katsuki T, Fujii M, Saito M: Exercise at ventilatory threshold aggravates left ventricular remodeling in patients with extensive anterior acute myocardial infarction. Am Heart J 2004, 147:113-120.

10. Giannuzzi P, Tavazzi L, Temporelli PL, Corra U, Imparato A, Gattone M, Giordano A, Sala L, Schweiger C, Malinverni C: Long-term physical training and left ventricular remodeling after anterior myocardial infarction: results of the Exercise in Anterior Myocardial Infarction (EAMI) trial. EAM Study Group. J Am Coll Cardiol 1993, 22:1821-1829.

11. Dubach P, Myers J, Dziekan G, Goebbels U, Reinhart W, Vogt P, Ratti R, Muller $P$, Miettunen $R$, Buser $P$ : Effect of exercise training on myocardial remodeling in patients with reduced left ventricular function after myocardial infarction: application of magnetic resonance imaging. Circulation 1997, 95:2060-2067.

12. Giallauria F, De Lorenzo A, Pilerci F, Manakos A, Lucci R, Psaroudaki M, D'Agostino M, Del Forno D, Vigorito C: Reduction of $\mathrm{N}$ terminal-pro-brain (B-type) natriuretic peptide levels with exercise-based cardiac rehabilitation in patients with left ventricular dysfunction after myocardial infarction. Eur J Cardiovasc Prev Rehabil 2006, 13:625-632.

13. Giallauria F, Lucci R, De Lorenzo A, D'Agostino M, Del Forno D, Vigorito C: Favourable effects of exercise training on $\mathrm{N}$-terminal pro-brain natriuretic peptide plasma levels in elderly patients after acute myocardial infarction. Age Ageing 2006, 35:601-607.

14. Koizumi T, Miyazaki A, Komiyama N, Sun K, Nakasato T, Masuda Y, Komuro I: Improvement of left ventricular dysfunction during exercise by walking in patients with successful percutaneous coronary intervention for acute myocardial infarction. Circ J 2003, 67:233-237.

15. Haykowsky MJ, Liang Y, Pechter D, Jones LW, McAlister FA, Clark AM: A meta-analysis of the effect of exercise training on left ventricular remodeling in heart failure patients: the benefit depends on the type of training performed. J Am Coll Cardiol 2007, 49:2329-2336.

16. Glasziou P, Chalmers I, Altman DG, Bastian H, Boutron I, Brice A, Jamtvedt G, Farmer A, Ghersi D, Groves T, et al: Taking healthcare interventions from trial to practice. BMJ 2010, 341:c3852

17. Jadad AR, Moore RA, Carroll D, Jenkinson C, Reynolds DJ, Gavaghan DJ, McQuay HJ: Assessing the quality of reports of randomized clinical trials: is blinding necessary? Control Clin Trials 1996, 17:1-12.

18. Lipsey M, Wilson D: Practical meta-analysis. Sage Publications, Thousand Oaks, Ca; 2001

19. Jette $M$, Heller $R$, Landry F, Blumchen $G$ : Randomized 4-week exercise program in patients with impaired left ventricular function. Circulation 1991, 84:1561-1567.

20. Heldal M, Rootwelt $K$, Sire S, Dale J: Short-term physical training reduces left ventricular dilatation during exercise soon after myocardial infarction. Scand Cardiovasc J 2000, 34:254-260.

21. Grodzinski $E$, Jette $M$, Blumchen $G$, Borer J: Effects of a four-week training program on left ventricular function as assessed by radionuclide ventriculography. J Cardiopulmonary Rehabil 1987, 7:517-524.

22. Ioannidis JPA, Patsopoulos NA, Evangelou E: Uncertainty in heterogeneity estimates in meta-analyses. BMJ 2007, 335:914-916.

23. Jugdutt BI: Prevention of ventricular remodelling post myocardial infarction: timing and duration of therapy. Can J Cardiol 1993, 9:103-114.

24. Ehsani AA, Biello DR, Schultz J, Sobel BE, Holloszy JO: Improvement of left ventricular contractile function by exercise training in patients with coronary artery disease. Circulation 1986, 74:350-358.

25. Belardinelli R, Georgiou D, Ginzton L, Cianci G, Purcaro A: Effects of moderate exercise training on thallium uptake and contractile response to low-dose dobutamine of dysfunctional myocardium in patients with ischemic cardiomyopathy. Circulation 1998, 97:553-561.

26. Dubach P, Myers J, Dziekan G, Goebbels U, Reinhart W, Muller P, Buser P, Stulz $P$, Vogt $P$, Ratti R: Effect of high intensity exercise training on central hemodynamic responses to exercise in men with reduced left ventricular function. J Am Coll Cardiol 1997, 29:1591-1598.

27. Malfatto G, Facchini M, Bragato R, Branzi G, Sala L, Leonetti G: Short and long term effects of exercise training on the tonic autonomic 
modulation of heart rate variability after myocardial infarction. Eur Heart J 1996, 17:532-538.

28. Vona M, Rossi A, Capodaglio P, Rizzo S, Servi P, De Marchi M, Cobelli F: Impact of physical training and detraining on endothelium-dependent vasodilation in patients with recent acute myocardial infarction. Am Heart J 2004, 147:1039-1046.

29. Suaya JA, Stason WB, Ades PA, Normand SL, Shepard DS: Cardiac rehabilitation and survival in older coronary patients. J Am Coll Cardiol 2009, 54:25-33.

30. Piepoli M, Corra U, Benzer W, Bjarnason-Wehrens B, Dendale P, Gaita D, McGee H, Mendes M, Niebauer J, Zwisler A, Schmid J: Secondary prevention through cardiac rehabilitation: physical activity counselling and exercise training: Key components of the position paper from the CardiacRehabilitation Section of the European Association of Cardiovascular Prevention and Rehabilitation. Eur Heart J 2010, 31:1967-1976.

31. Dafoe W, Arthur H, Stokes H, Morrin L, Beaton L: Universal access: but when? Treating the right patient at the right time: access to cardiac rehabilitation. Can J Cardiol 2006, 22:905-911.

32. Clark AM, Hartling L, Vandermeer B, McAlister FA: Meta-analysis: secondary prevention programs for patients with coronary artery disease. Ann Intern Med 2005, 143:659-672.

33. Kovoor P, Lee AK, Carrozzi F, Wiseman V, Byth K, Zecchin R, Dickson C, King $M$, Hall J, Ross DL, et al: Return to full normal activities including work at two weeks after acute myocardial infarction. Am J Cardiol 2006, 97:952-958.

34. Senaratne MP, Smith G, Gulamhusein SS: Feasibility and safety of early exercise testing using the Bruce protocol after acute myocardial infarction. J Am Coll Cardiol 2000, 35:1212-1220.

35. Parker k, Hauer T, Arena R, Lundberg D, Aggarwal S, Goodhart D, D. T: Attendance in an early discharge clinic with symptom limited maximal exercise testing is safe and improves cardiac rehabilitation participation among low-risk stemi patients. Eur J Cardiovasc Prev Rehabil 2009, 16.

36. Clark AM, Hartling L, Vandermeer B, McAlister FA: Secondary prevention program for patients with coronary artery disease: A meta-analysis of randomized control trials. Ann Int Med 2005, 143:659-672.

37. Taylor RS, Brown A, Ebrahim S, Jolliffe J, Noorani H, Rees K, Skidmore B, Stone J, Thompson DR, Oldridge N: Exercise-based rehabilitation for patients with coronary heart disease: systematic review and metaanalysis of randomized controlled trials. Am J Med 2004, 116:682-692.

38. Kotseva K, D W, De Backer G, De Bacquer D, Pyörälä K, Keil U, ftESG: Cardiovascular prevention guidelines in daily practice: a comparison of EUROASPIRE I, II, and III surveys in eight European countries. Lancet 2009, 373:929-940.

39. Bjarnason-Wehrens B, McGee H, Zwisler AD, Piepoli MF, Benzer W, Schmid JP, Dendale P, Pogosova NG, Zdrenghea D, Niebauer J, et al: Cardiac rehabilitation in Europe: results from the European Cardiac Rehabilitation Inventory Survey. Eur J Cardiovasc Prev Rehabil 2010, 17:410-418.

40. Dalal HM, Zawada A, Jolly K, Moxham T, Taylor RS: Home-based versus centre based cardiac rehabiltiation: Cochrane systematic review and meta-analysis. BMJ 2010, 340:b5631.

doi:10.1186/1745-6215-12-92

Cite this article as: Haykowsky et al:: A Meta-analysis of the effects of Exercise Training on Left Ventricular Remodeling Following Myocardial Infarction: Start early and go longer for greatest exercise benefits on remodeling. Trials 2011 12:92.

\section{Submit your next manuscript to BioMed Central and take full advantage of:}

- Convenient online submission

- Thorough peer review

- No space constraints or color figure charges

- Immediate publication on acceptance

- Inclusion in PubMed, CAS, Scopus and Google Scholar

- Research which is freely available for redistribution

Submit your manuscript at www.biomedcentral.com/submit
C Biomed Central 